\title{
European Water Utility Management: Promoting Efficiency, Innovation and Knowledge in the Water Industry
}

\author{
Giulia Romano ${ }^{1}$ - Andrea Guerrini ${ }^{2}$. \\ Rui Cunha Marques ${ }^{3}$
}

Published online: 4 May 2017

(C) Springer Science+Business Media Dordrecht 2017

In the European Union, the Water Framework Directive (2000/60/EC) is based on the idea that water management needs to take into account economic, ecological and social issues, and that its major objective is the sustainable and efficient use and management of water resources. In the coming years, European water resources will be placed under further pressure by many factors, such as population growth, urbanization and climate change. Therefore, policymakers and water utility managers face the puzzle of balancing the increasing human demand for water and the protection of the ecosystems' sustainability, fueling the on-going search for the best practices and learning by doing in water utility management that produce superior performance.

In the light of the current challenges on resource efficiency and performance improvement, the promotion of innovation and benchmark activities within the water industry is a cutting edge issue for the European Union.

Efficiency, Innovation and Knowledge are the key elements to improve performance and well-being in Europe. They should be the focus of the best efforts of European and national policies, firm's strategies and citizens' attitudes. With reference to the water industry, they have been considered as priorities in Europe for many years. Even if they have not been fully

Giulia Romano

giulia.romano@unipi.it

Andrea Guerrini

andrea.guerrini@univr.it

Rui Cunha Marques

rui.marques@tecnico.ulisboa.pt

Department of Economics and Management, University of Pisa, Via C. Ridolfi, 10, 56124 Pisa, Italy

2 Department of Business Administration, University of Verona, Via dell'Artigliere, 19, 37129 Verona, Italy

3 CESUR, CERIS, IST, Universidade de Lisboa, Avenida Rovisco Pais, no.1, 1049-001 Lisbon, Portugal 
achieved, many empirical studies have shown up that the efficiency of utilities should be improved throughout Europe. Unlike the USA, in the European countries has this only recently been investigated in order to better understand the potentialities in terms of efficiency growth (Berg and Marques 2011).

The literature still faces the need of identifying and discussing in depth current relevant experiences of benchmarking in water utility management and regulation that characterize different European countries in order to identify the relevance, usefulness and potential crossborder diffusion of these activities, making them trans-boundary strategies, policies and actions. Bearing this in mind, the European water management system could become a collaborative catalyst of methods and tools for setting, maintaining and improving best practices in utility management.

This special issue intends to foster relationships via discussion, creation and dissemination of relevant and cutting-edge European water utility management issues by bringing together outstanding international scholars and contribute positively to the research agenda. The emphasis will be on research that accounts for cutting-edge European water utility management issues, such as experiences in benchmarking (management and regulatory impacts) and attempts to highlight best practices to be spread throughout European countries.

A network of European and International scholars has been created after the International Seminar held at the University of Pisa in June 2015 and integrated in the European Jean Monnet EWUM Project, sponsored by the European Commission Erasmus + Programme Jean Monnet Action (Project number 553224-EPP-1-2014-1-IT-EPPJMO-MODULE).

This event brought scholars to discuss the most relevant and cutting edge issues about water utilities and water management in Europe and all over the world. An annual international seminar to be held in different European Universities each year is an opportunity for this growing research community to meet, discuss and create knowledge to be spread throughout Europe. In 2016 the second International seminar was held in Oviedo (Spain) and in 2017 the third in Pisa again to discuss the main results of the activities of a research project financed by the University of Pisa (PRA 2016).

This special issue collected the best papers presented and discussed in the Pisa seminar in June 2015.

The comparison of different ownership structure is a highly debated issue with economic, socio-environmental, and political implications. Different ownership structures could affect tariffs, investments, operating and capital expenses. One of the social implications of the choice among alternative ownership structures would be the greater affordability and equity of water services for all citizens through lower tariffs charged by wholly owned public water utilities in comparison to what occurs with private investors. Furthermore, a negative socioenvironmental implication is the poor quality of service due to the low amount of investments carried out, with high environmental risks. Finally, a political effect could be the re-election of majors by customers-voters pursued by applying low water tariffs. With reference to the broad theme of governance and ownership structure of water utilities and its impact on performance, sustainability, and regulatory schemes, the paper of Marta Suárez-Varela et al. deals with the investigation of the link between ownership and performance in water utilities, discussing in depth if private utilities really perform differently from public ones. By selecting a sample of Spanish water utilities, the paper measures their efficiency through directional distance functions, metafrontiers and Data Envelopment Analysis (DEA) techniques, and highlights that private management is more efficient in the use of labor input, while public management gets higher savings on other OPEX items. 
Piergiorgio Novaro and Jacopo Bercelli (2016) provides a critical perspective of the privatization process in the light of European experiences. The paper is focused on the referenda carried out in Italy and Germany, and on the role of local government decisions on re-nationalization of utilities, as occurred in France. This analysis was developed in view of the Directives 2014/13/EU and 2014/25/EU that exclude the application of a mandatory externalization (contracting out) for the water sector.

Other papers are focused on performance, but deal with this issue from different perspectives. Maria Molinos-Senante et al. (2016) apply the Färe-Primont productivity index (FPI) to evaluate the productivity change for the 10 water and sewerage companies and 12 water only companies in England and Wales and illustrated the importance of using a reliable index to compute the productivity change of water companies when the performance of companies is used to set water tariffs. Their results indicate that during the first period analyzed (2001-2004) productivity improved, mainly due to gains in efficiency whereas technical change remained constant. During the following years (2005-2008) productivity showed a declining trend and any gains in efficiency were lost to the highly negative technical change on productivity growth.

Alexandros Maziotis et al. (2016) measure performance by integrating efficiency and quality in a Malmquist-Luenberger index for 22 utilities of England and Wales: the paper shows that water utility regulators need to introduce quality measures in their tools for yardstick competition, to achieve an effective benchmarking and fairer tariffs. Quality is a dimension of water services that has been usually omitted in the study of performance of water utilities although quality matters in the measurement of technical efficiency (Simões and Marques 2012). As a matter of fact, by avoiding the use of quality-based measurement of efficiency the utilities that produce higher quality services could be penalized, since maintaining high levels of quality requires the use of resources that could otherwise be devoted to increase the quantity of the service produced (Picazo-Tadeo et al. 2008). So, the difference between conventional and quality-adjusted evaluations represents the opportunity cost of maintaining quality.

A basic approach to water utilities performance measurement is focused on technical efficiency and costs; a more advanced method integrates service quality and cost/efficiency measures to obtain an overall performance index. An interesting approach to measure the multiple benefits generated by a water infrastructure is developed by Bethany Cooper et al. (2016) who outline how amenity and ecological benefits of waterways are generated. This paper follows a third approach to performance evaluation based not only on service quality and cost performance, but also on the improvement of city's livability created by water infrastructure.

The achievement of economies of scale is another debated issue in the water sectors across Europe. For example, in countries such as Italy, small and medium utilities coexist with big players as ACEA, IREN, and Hera. Most studies confirmed the presence of economies of scale in the water industry, but several others found diseconomies of scale in various countries (see for references Berg and Marques 2011). Many studies on economies of scale propose that only small- and medium-sized firms can improve efficiency through expansion and that big firms do not always benefit through expansion and sometimes even experience diseconomies (De Witte and Marques 2011; Carvalho and Marques, 2014, 2015; Marques and De Witte 2011). Graziano Abrate et al. (2016) investigate the potential benefits of the process of consolidation adoption and ex ante merger hypothesis based on Bogetoft and Wang's 2005 decomposition of potential gains from aggregation. The study does not prove that all water utilities are 
positively affected by economies of scale, and it requires a case by case approach in evaluating the benefits from merger projects.

Guerrini et al. (2017) study the main efficiency drivers of 139 Tuscan Wastewater Treatment Plants (WWTPs) by using an ordinary least squares analysis of total plant costs regressed on a set of 28 exogenous variables and a two-stage Data Envelopment Analysis model, where efficiency scores are obtained through weight restrictions. Moreover, the results of this study demonstrate that larger scale of operations and the higher usage of the productive capacity (grouped as "other features of WWTPs") can improve cost efficiency.

The last three papers of this special issue are related to stakeholder engagement, regulatory constructivism, and tariff setting.

A stakeholder driven approach is recommended by several international organisms with laws, general accepted standards and guidelines: the EU Water Framework Directive suggests involving citizens in the development of water governance; OECD developed guidelines for an effective stakeholders engagement, also observing some best practices adopted in Europe (OECD, 2015). Alberto Ruiz-Villaverde et al. (2016) make a literature review to cover this issue, looking for successful experiences in EU countries. The paper describes also the main limitations and difficulties to implement a public participation water management, by studying the Spanish case.

Eduardo Araral et al. (2016) claim that beliefs (as orientation toward "privatization", "regulation", etc.) play a relevant role in the development of water governance model and regulatory framework and show this conventional view with an extended empirical survey on regulators and managers in Italy and China. The argument that policy ideas are crucial in the policy process is not new, but there is a scarcity of empirical work investigating the ideal sphere of public policies. The evidence that the presence of a variety of ideas characterizes a policy system corroborates the claim that a pool of actors of the policy network may plan the adoption of alternative policy options. The Q method aims to highlight that the views of groups of individuals (regulators and politicians) are characterized by a subjective structure. Differently from other model of qualitative research, data are not only interpreted by the researcher, but also handled with a statistical approach.

Finally, Angelo Antoci et al. (2016), deal the water pricing mechanism that sets tariffs for non-domestic customers of water utilities. This paper shows a dynamic evolutionary model where two sectors (A and B) competes for water: any under(over)estimation of water prices really affects the dynamics of the model moving the equilibrium from a point where the less water- consuming sector is favorite to another where the same sector is penalized.

Therefore, this set of papers makes this special issue a sound contribution for the literature on water utility management, promoting the knowledge and, consequently, the efficiency and innovation in this essential sector.

\section{References}

Abrate G, Bruno C, Erbetta F et al (2016) Water Resour Manag. doi:10.1007/s11269-016-1376-9

Antoci A, Borghesi S, Sodini M (2016) Water Resour Manag. doi:10.1007/s11269-016-1391-X

Araral E, Asquer A, Wang Y (2016) Water Resour Manag. doi:10.1007/s11269-016-1496-2

Berg S, Marques R (2011) Quantitative studies of water and sanitation utilities: a benchmarking literature survey. Water Policy 13(5):591-606

Carvalho P, Marques R (2014) Computing economies of vertical integration, economies of scope and economies of scale using partial frontier nonparametric methods. Eur J Oper Res 234(1):292-307 
Carvalho P, Marques R (2015) Estimating size and scope economies in the Portuguese water sector using the most appropriate functional form. Eng Econ 60(2):109-137

Cooper, B., Crase, L., Maybery, D. (2016), Pushing the governance boundaries: making transparent the role of water Utilities in Managing Urban Waterways, water Resour Manage (2016). doi:10.1007/s11269-016$1457-9$

De Witte K, Marques R (2011) Big and beautiful? On non-parametrically measuring scale economies in nonconvex technologies. J Prod Anal 35(3):213-230

Guerrini A, Romano G, Carosi L et al (2017) Water Resour Manag. doi:10.1007/s11269-017-1586-9

Marques R, De Witte K (2011) Is big better? On scale and scope economies in the Portuguese water sector. Econ Model 28(3):1009-1016

Maziotis A, Molinos-Senante M, Sala-Garrido R (2016) Water Resour Manag. doi:10.1007/s11269-016-1395-6

Molinos-Senante M, Maziotis A, Sala-Garrido R (2016) Water Resour Manag. doi:10.1007/s11269-016-1346-2 http://link.springer.com/article/10.1007/s11269-016-1346-2

Novaro P, Bercelli J, Water Resour Manage (2016) Water services are the bridgehead for a return to publicly owned Utilities in Europe. A Comparative Analysis. doi:10.1007/s11269-016-1535-z

Picazo-Tadeo AJ, Saez-Fernandez FJ, Gonzalez-Gomez F (2008) Does service quality matter in measuring the performance of water utilities? Util. Policy 16(1):30-38

Ruiz-Villaverde A, García-Rubio MA (2016) Public participation in European water management: from theory to practice, water Resour Manage (2016). doi:10.1007/s11269-016-1355-1

Simões P, Marques R (2012) Influence of regulation on the productivity of waste utilities. What can we learn with the Portuguese experience? Waste Manag 32(6):1266-1275

Suárez-Varela M, de los Ángeles García-Valiñas M, González-Gómez F et al (2016) Ownership and performance in water services revisited: does private management really outperform public? Water Resour Manag 2016. doi:10.1007/s11269-016-1495-3 